\title{
Analysis of Risk Factors Associated With Preterm Delivery After Fetoscopic Laser Surgery for TTTS
}

Genxia Li ( $\sim$ ligenxia@163.com )

The Third Affiliated Hospital of Zhengzhou University https://orcid.org/0000-0002-5926-2553

Shuhui Chu

The Third Affiliated Hospital of Zhengzhou University

Shihong Cui

The Third Affiliated Hospital of Zhengzhou University

Yajuan Xu

The Third Affiliated Hospital of Zhengzhou University

Hezhou Li

The Third Affiliated Hospital of Zhengzhou University

\section{Fan Feng}

The Third Affiliated Hospital of Zhengzhou University

\section{Li Dong}

The Third Affiliated Hospital of Zhengzhou University

\section{Chunhua Cheng}

The Third Affiliated Hospital of Zhengzhou University

Jiao Li

The Third Affiliated Hospital of Zhengzhou University

\section{Mingkun Xie}

The Third Affiliated Hospital of Zhengzhou University

\section{Shuo Feng}

The Third Affiliated Hospital of Zhengzhou University

\section{Junya Zhang}

The Third Affiliated Hospital of Zhengzhou University

\section{Manman Yang}

The Third Affiliated Hospital of Zhengzhou University

\section{Mengyu Li}

The Third Affiliated Hospital of Zhengzhou University

\section{Yujing Hao}

The Third Affiliated Hospital of Zhengzhou University

\section{Research Article}


Keywords: Twin to twin transfusion syndrome, Fetoscopic laser surgery, Preterm delivery, Pathogenesis Posted Date: December 17th, 2021

DOI: https://doi.org/10.21203/rs.3.rs-1035290/v1

License: (c) (1) This work is licensed under a Creative Commons Attribution 4.0 International License. Read Full License 


\section{Abstract \\ Objective}

Fetoscopic laser surgery (FLS) is currently the standard treatment for twin to twin transfusion syndrome (TTTS). This study aims to improve the perinatal outcomes of TTTS patients by analyzing the risk factors associated with preterm delivery after FLS for TTTS.

\section{Methods}

A prospective cohort study was conducted in 97 cases of patients with TTTS who underwent FLS at the Third Affiliated Hospital of Zhengzhou University from May 2018 to December 2020. A multivariate logistic regression model was used to determine the risk factors associated with preterm delivery. Finally, ROC curve was utilized to analyze the diagnostic value of related risk factors.

\section{Results}

A total of 90 TTTS patients were included in the study. There were 37 cases in group A and 53 cases in group $B$. Through multivariate logistic regression model analysis, three risk factors related to the gestational age of childbirth $<32$ weeks were identified: preoperative $\mathrm{CL}<27.5 \mathrm{~mm}(\mathrm{OR}, 10.9 ; P<0.001)$, PPROM (OR, 4.0; $P=0.024)$, placental abruption (OR, 17.6; $P=0.018)$. ROC curve analysis suggested that the AUC of the combined diagnosis of the three factors was $0.799(P<0.001)$, which has a high value for predicting preterm delivery at low gestational age.

\section{Conclusion}

Multivariate logistic regression analysis demonstrated that $\mathrm{CL}<27.5 \mathrm{~mm}, \mathrm{PPROM}$ and placental abruption were connected with preterm delivery before 32 weeks of pregnancy. Identifying and intervening the corresponding risk factors can improve the pregnancy and neonatal outcomes after fetoscopic surgery, and promote the improvement of fetoscopic surgery techniques.

\section{Introduction}

Twin to twin transfusion syndrome (TTTS) occurs in all pregnancies at a rate of 1/10000-3/10000 [1], affecting approximately $10 \%-15 \%$ of monochorionic diamniotic twin gestations [2]. The Quintero staging system is the most commonly used staging method for TTTS, which can be divided into stage I-V. If TTTS at stage II-IV is not treated, the perinatal mortality rate will reach $80 \%-90 \%$ due to intrauterine death, miscarriage, and very premature delivery [3]. There is evidence that fetoscopic laser surgery (FLS) is superior to continuous amniotic fluid reduction surgery in terms of perinatal survival and neurological outcomes at TTTS II-IV stages [4], and it is currently the best management plan for patients with severe 
second trimester TTTS $[5,6]$, with the survival rate of at least one child over $90 \%$. The dual twin survival rate after FLS is about 70\% [7], therefore FLS can significantly improve the pregnancy outcome of patients with TTTS. However, preterm delivery is still a major challenge, which determines the morbidity and mortality of surviving infants. The risk of delivery before 28 weeks of gestation is about $17-22 \%$ in TTTS patients after FLS, and the risk of delivery before $32-34$ weeks of gestation is about $29-54 \%[5,8,9]$. It has been reported that the morbidity of severe neurodevelopmental disorders (cerebral palsy, bilateral blindness and/or deafness, severe cognitive and/or motor delay) in children after FLS within two years is $10.5 \%$ [10], and $10 \%$ of the children have long-term neurological damage after FLS, and preterm delivery is an independent risk factor for neurological damage after fetoscopic surgery [11]. According to literature reports [12], low gestational age at delivery is the only factor significantly associated with complex adverse pregnancy outcomes (respiratory complications). Improving the gestational age at delivery is the next important challenge to improve pregnancy outcomes, and identifying the risk factors associated with preterm delivery in patients with TTTS after fetoscopic surgery is the first step. However, the cause of preterm delivery is not fully understood. Studies have found that pregnancy and surgical characteristics are important predictors of preterm delivery in patients. For example, studies have confirmed that the short cervical canal before surgery is a risk factor for preterm delivery [13], which mainly leads to spontaneous preterm delivery [14]. A recent study by Chmait et al. [15] showed that the position of trocar insertion, especially the outside of the lower uterine segment, was associated with the risk of PROM within 21 days after FLS. Hessami K et al. [16] found that preterm delivery before 32 weeks of gestation was significantly related to the risk of neurodevelopment impairment (NDI) in later childhood through analyzing the Cut-off values of different gestational weeks. The goal of this study is to observe the gestational age distribution of patients with TTTS at delivery treated by FLS, and to analyze the characteristics of the operation and the perinatal period to determine the relevant risk factors for preterm delivery before 32 weeks of gestation.

\section{Materials And Methods}

\subsection{General information}

The data on 97 cases of TTTS patients who underwent FLS at the Third Affiliated Hospital of Zhengzhou University from May 2018 to December 2020 were prospectively preliminarily collected. Among the 97 patients, 2 cases of monochorionic monoamniotic pregnancy, 1 case of dichorionic diamniotic pregnancy, 1 case of dichorionic triamniotic pregnancy, 1 case of monochorionic triamniotic pregnancy, and 2 cases of second operation were excluded. Therefore, a total of 90 TTTS patients after FLS were enrolled in the study group. The average age of the patients was $28.5 \pm 5.0$ years (17-40 years old). Then the patients were divided into 2 groups according to the pregnancy outcome: group A: gestational age at birth $<32$ weeks; group B: gestational age at birth $\geq 32$ weeks. This study was approved by the Medical Ethics Committee of the Third Affiliated Hospital of Zhengzhou University. The patients were told about the risks associated with the surgery, and the informed consent of the patients and their families was obtained. 


\subsection{TTTS diagnostic criteria and staging of TTTS}

A comprehensive ultrasound examination was performed in all pregnant women with monochorionic diamniotic twin pregnancies, and TTTS was diagnosed through the evaluation of the fetal intervention team and preoperatively staged according to Quintero criteria. FLS was conducted in the TTTS patients at stage II to IV between 16 to 29 weeks of gestation, and TTTS patients at stage I with severe symptoms (shortened cervical canal, excessive amniotic fluid causing discomfort to the pregnant women, etc.). Preoperative and postoperative cervical canal length was measured by transvaginal ultrasound in all patients, and whether a cervical cerclage was proceeded based on cervical canal length and the wishes of the patient and family members.

\subsection{Surgical Methods}

Before the operation, the patient was fasted for 8 hours and water was forbidden for 4 hours. Then, the patient was given oral indomethacin to suppress contractions at 30 minutes prior to surgery. The local anesthesia combined with intravenous anesthesia, regional anesthesia and general anesthesia were optional as anesthesia methods. The puncture cannula was inserted percutaneously under ultrasound guidance, amniotic fluid was collected for fetal chromosome examination when necessary. The anastomotic branches of placenta was searched under a fetoscope, and the target anastomotic branches were coagulated. Antibiotics were given to patients to prevent infection after surgery. Subsequently, fetal preservation treatment was implemented according to the uterine contractions of the patients. One day after the operation, ultrasound examination and Doppler blood flow examination were performed to observe the changes of amniotic fluid volume and blood flow changes in the donor and recipient infants. According to the condition and willingness of patients, they were selected to deliver in our hospital or another hospital. The delivery data of the hospital and the follow-up institutions were prospectively collected through follow-up.

\subsection{Observation Indicators}

(1) The following preoperative variables were collected: maternal demographics (age, parity, history of premature delivery), Quintero standard staging, preoperative cervical length (transvaginal measurement), preoperative amniotic fluid AFV, placental location. (2) Intraoperative variables included anesthesia method, cannulas diameter, entry method, surgical method, whether the puncture hole was blocked, whether the diaphragm was damaged, and the amount of amniotic fluid reduction. (3) Postoperative variables were collected: amniotic fluid leakage, chorioamnionitis, PPROM, placental abruption, one fetal death in utero, gestational week of delivery, total live birth rate, 28-day survival rate of at least one child and 28-day survival rate of twins.

\subsection{Statistical Methods}


The SPSS 25 software and GraphPad Prism software were used for statistical analysis and mapping. The independent sample $t$-test was used to compare the continuous variables that that conformed to the normal distribution, and the Mann-Whitney $U$ test was used for the analysis of the non-parametric variables. For binary variables, the Chi-square test was used. When one theoretical frequency $\geq 1$ and $<5$, the corrected Chi-square test was used; while when at least two theoretical frequencies $\geq 1$ and $<5$, the Fisher exact test was performed. Kendall correlation coefficient test was used for rank variables. Furthermore, the optimal threshold of cervical length and AFV in the recipients were calculated using receiver operating characteristic (ROC) curve analysis and Youden's index, in order to determine the risk of preterm delivery. A multivariate logistic regression model was used to analyze the correlation between the gestational week of delivery and various variables, and the risk factors were screened. The ROC curve was drawn and the area under the curve (AUC) was calculated. The larger the AUC was, the better the diagnostic value was, which could be used to evaluate the diagnostic value.

\section{Results}

\subsection{Analysis of the general situation of patients with TTTS who underwent FLS}

According to Quintero staging system, 18 cases (20.0\%) were in TTTS stage I, 19 cases $(21.1 \%)$ were in TTTS stage II, 37 cases (41.1\%) were in TTTS stage III, and 16 cases (17.8\%) were in TTTS stage IV. The distribution of gestational age at surgery and gestational age at delivery in 90 cases of TTTS patients after FLS were analyzed. As shown in Figure 1 and Figure 2, the average gestational age at surgery was 22.2 \pm 3.3 weeks (range: $16.14-28.86$ weeks) and the average gestational age at delivery was $32.1 \pm 4.1$ weeks (range: 22.57-38.71 weeks). The total live birth rates at delivery during TTTS stage I, II, III, and IV were $94.4 \%, 76.3 \%, 66.2 \%$, and $81.2 \%$, respectively. The survival rates of at least one child were $94.4 \%$, $78.9 \%, 83.8 \%$, and $100 \%$, respectively. The survival rates of twin fetus were $94.4 \%, 73.7 \%, 48.6 \%, 62.5 \%$, respectively. According to Kendall correlation coefficient test, there was no significant difference in the survival rate of at least one child at each stage $(P=0.578)$, while the survival rate of twins had significant prognostic significance $(P=0.008)$ (Figure 3$)$. The correlation between the survival rate of twins and TTTS stage was further analyzed by multivariate logistic regression analysis. The results indicated that the survival rates of twins at TTTS stage III $(P=0.008)$ and TTTS stage IV $(P=0.044)$ were smaller than that at TTTS stage I, and the difference was statistically significant. There was no statistical difference in the survival rates of twins between TTTS stage I and TTTS stage II $(P>0.05)$ (Table1). 
Table 1

Logistic regression analysis of the correlation between twin survival rate and TTTS stage

\begin{tabular}{|lllll|}
\hline stages & twin survival rate (\%) & $\boldsymbol{P}$ value & $\operatorname{Exp}(\mathrm{B})$ & $\mathbf{9 5 \%}$ confidence interval (Cl) of $\operatorname{Exp}(\mathrm{B})$ \\
\hline TTTS I & 94.4 & 0.030 & $\backslash$ & $\backslash$ \\
\hline TTTS II & 73.7 & 0.118 & 0.165 & $0.017-1.579$ \\
\hline TTTS III & 48.6 & 0.008 & 0.056 & $0.007-0.463$ \\
\hline TTTS IV & 62.5 & 0.044 & 0.098 & $0.010-0.936$ \\
\hline
\end{tabular}

\subsection{Analysis of the risk factors related to preterm delivery in patients after FLS for TTTS}

Preoperative indicators: The numbers of patients with preoperative $\mathrm{CL}<27.5 \mathrm{~mm}$ were $21 / 37(56.8 \%)$ in group A and 12/53 (22.6\%) in group B; Recipient's AFV > $139.5 \mathrm{~mm}$ was $13 / 37$ (35.1\%) in group A and $5 / 53(9.4 \%)$ in group $B$; The average preoperative $C L$ was $26.5 \pm 7.5 \mathrm{~mm}$ in group $A$ and $29.1 \pm 5.6 \mathrm{~mm}$ in group $B$. The difference analysis between groups suggested that there were statistically significant differences between the two groups in the number of patients with preoperative $\mathrm{CL}<27.5 \mathrm{~mm}(P=0.01)$, recipient's AFV $>139.5 \mathrm{~mm}(P=0.03)$ and the average preoperative $\mathrm{CL}(P=0.044)$. However, there were no significant difference in maternal age, parity, placental previa, preoperative AFV of recipient, concurrent twin anemia-polycythemia sequence (TAPS), selective intrauterine growth restriction (sIUGR) and other indicators between group A and group B. The results were shown in Table 2.

Intraoperative surgical variables: The numbers of patients without cervical cerclage were $31 / 37$ (83.8\%) in group $A$ and $51 / 53(96.2 \%)$ in group B. There was a statistically significant difference in this index between the two groups $(P=0.049)$. However, there were no significant differences in gestational age, trocar diameter distribution (8F/10F), Solomon operation, gel sponge or hemostatic gauze for puncture hole sealing, and average amniotic fluid reduction during surgery. The results are displayed in Table 2.

Postoperative indicators: The number of patients with amniotic fluid leakage were $3 / 37$ (8.1\%) in group A and $3 / 53(5.7 \%)$ in group $B$; The number of patients with chorioamnionitis were $3 / 37$ (8.1\%) in group $A$ and $2 / 53(3.8 \%)$ in group $B$; The number of PPROM were $22 / 37$ (59.5\%) in group $A$ and $14 / 53(26.4 \%)$ in group $B$; The numbers of placental abruption were 8/37 (21.6\%) in group $A$ and 1/53 (1.9\%) in group B; The numbers of intrauterine deaths in one fetus were $6 / 37$ (16.2\%) in group $A$ and $14 / 53(26.4 \%)$ in group B. Among them, the number of PPROM $(P=0.002)$ and the number of placental abruption $(P=0.007)$ were statistically different between the two groups, while the differences in other indicators were not statistically significant. The results are exhibited in Table 2. 
Table 2

The perinatal and surgical characteristics of gestational age $<32$ weeks and $\geq 32$ weeks

\begin{tabular}{|c|c|c|c|c|}
\hline Variable & $\begin{array}{l}\text { Among those } \\
\text { delivering }<32 \text { weeks } \\
(n=38)\end{array}$ & $\begin{array}{l}\text { Among those } \\
\text { delivering } \geq 32 \text { weeks } \\
\text { ( } n=52)\end{array}$ & $\begin{array}{l}P \\
\text { value }\end{array}$ & $\mathrm{OR}(95 \% \mathrm{Cl})$ \\
\hline \multicolumn{5}{|c|}{ Categorical (frequency of characteristic) } \\
\hline Stage of TTTS I+II / III+IV & $18 / 37(48.6 \%)$ & $19 / 53(35.6 \%)$ & 0.225 & $\begin{array}{l}0.590(0.251- \\
1.387)\end{array}$ \\
\hline Multipara & $20 / 37(54.1 \%)$ & $25 / 53(47.2 \%)$ & 0.520 & $\begin{array}{l}1.318(0.568- \\
3.058)\end{array}$ \\
\hline $\begin{array}{l}\text { Preoperative cervical } \\
\text { length }<27.5 \mathrm{~mm}\end{array}$ & $21 / 37(56.8 \%)$ & $12 / 53(22.6 \%)$ & 0.001 & $\begin{array}{l}4.484(1.796- \\
11.194)\end{array}$ \\
\hline Nonposterior placenta & 23/37(62.2\%) & $24 / 53(45.3 \%)$ & 0.115 & $\begin{array}{l}1.985(0.843- \\
4.676)\end{array}$ \\
\hline $\begin{array}{l}\text { Recipient's AFV } \\
>139.5 \mathrm{~mm}\end{array}$ & $13 / 37(35.1 \%)$ & $5 / 53(9.4 \%)$ & 0.003 & $\begin{array}{l}5.200(1.660- \\
16.290)\end{array}$ \\
\hline Trocar diameter(8F/10F) & $20 / 37(54.1 \%)$ & $33 / 53(62.3 \%)$ & 0.436 & $\begin{array}{l}1.403(0.598- \\
3.289)\end{array}$ \\
\hline Solomon & $28 / 37(75.7 \%)$ & $31 / 53(58.5 \%)$ & 0.091 & $\begin{array}{l}2.208(0.872- \\
5.589)\end{array}$ \\
\hline Sealing of puncture hole & $28 / 37(75.7 \%)$ & $47 / 53(88.7 \%)$ & 0.103 & $\begin{array}{l}2.518(0.810- \\
7.826)\end{array}$ \\
\hline Without cervical cerclage & $31 / 37(83.8 \%)$ & $51 / 53(96.2 \%)$ & 0.049 & $\begin{array}{l}0.203(0.038- \\
1.067)\end{array}$ \\
\hline TAPS & $2 / 37(5.4 \%)$ & $4 / 53(7.5 \%)$ & 0.521 & $\begin{array}{l}0.700(0.121- \\
4.036)\end{array}$ \\
\hline SIUGR & $4 / 37(10.8 \%)$ & 7/53(13.2\%) & 0.438 & $\begin{array}{l}0.797(0.216- \\
2.944)\end{array}$ \\
\hline Amniotic fluid leakage & $3 / 37(8.1 \%)$ & $3 / 53(5.7 \%)$ & 0.479 & $\begin{array}{l}1.471(0.280- \\
7.723)\end{array}$ \\
\hline Chorioamnionitis & $3 / 37(8.1 \%)$ & $2 / 53(3.8 \%)$ & 0.333 & $\begin{array}{l}2.250(0.357- \\
14.182)\end{array}$ \\
\hline $\begin{array}{l}\text { Preterm premature } \\
\text { rupture of membranes } \\
\text { (PPROM) }\end{array}$ & $22 / 37(59.5 \%)$ & $14 / 53(26.4 \%)$ & 0.002 & $\begin{array}{l}4.086(1.667- \\
10.013)\end{array}$ \\
\hline Placental abruption & $8 / 37(21.6 \%)$ & $1 / 53(1.9 \%)$ & 0.007 & $\begin{array}{l}14.345(1.708- \\
120.457)\end{array}$ \\
\hline $\begin{array}{l}\text { Single intrauterine fetal } \\
\text { death }\end{array}$ & 6/37(16.2\%) & $14 / 53(26.4 \%)$ & 0.252 & $\begin{array}{l}0.539(0.186- \\
1.566)\end{array}$ \\
\hline
\end{tabular}




\begin{tabular}{|c|c|c|c|c|}
\hline Variable & $\begin{array}{l}\text { Among those } \\
\text { delivering }<32 \text { weeks } \\
(n=38)\end{array}$ & $\begin{array}{l}\text { Among those } \\
\text { delivering } \geq 32 \text { weeks } \\
\text { ( } n=52)\end{array}$ & $\begin{array}{l}P \\
\text { value }\end{array}$ & $\mathrm{OR}(95 \% \mathrm{Cl})$ \\
\hline \multicolumn{5}{|c|}{ Continuous, mean \pm SD Median (range) } \\
\hline Maternal age, y & $27.9 \pm 4.4$ & $28.9 \pm 5.3$ & 0.278 & \\
\hline $\begin{array}{l}\text { Gestational age at } \\
\text { surgery, wks }\end{array}$ & $22.5 \pm 3.1$ & $21.9 \pm 3.3$ & 0.436 & \\
\hline $\begin{array}{l}\text { Preoperative AFV of } \\
\text { recipient, } \mathrm{cm}\end{array}$ & $11.9 \pm 3.2$ & $11.0 \pm 2.5$ & 0.189 & \\
\hline $\begin{array}{l}\text { Preoperative cervical } \\
\text { length, } \mathrm{mm}\end{array}$ & $26.5 \pm 7.5$ & $29.1 \pm 5.6$ & 0.044 & \\
\hline $\begin{array}{l}\text { Reduced volume of } \\
\text { amniotic fluid, ml }\end{array}$ & $1133.8 \pm 665.4$ & $1152.8 \pm 809.3$ & 0.834 & \\
\hline
\end{tabular}

Further, the optimal threshold of CL (Figure 4A) and recipient's AFV (Figure 4B) were calculated using ROC curve analysis and Youden's index. When $\mathrm{CL}<27.5 \mathrm{~mm}$, the risk of delivery $<32$ weeks was greater $(P=0.001) ; \mathrm{AFV}>139.5 \mathrm{~mm}$ was significantly correlated with delivery before 32 weeks of gestation $(P=0.003)$.

Through collinearity analysis (Table 3), the collinearity of all independent variables was not statistically significant (all VIF<10.0). All independent variables were included in the logistic regression model to test the relationship between pregnancy and surgical characteristics with outcome of premature delivery. Three associated risk factors for the gestational age of delivery $<32$ weeks were identified: preoperative $\mathrm{CL}<27.5 \mathrm{~mm}$ (OR, 8.4; 95\% Cl, 1.8-38.6; $P=0.006$ ), PPROM (OR, 4.3; 95\% Cl, 1.1-16.9; $P=0.036$ ), placental abruption (OR, 17.3; $95 \% \mathrm{Cl}, 1.1-276.2 ; P=0.043)$. The logistic regression equation is:

$P=1 /(1+\operatorname{Exp}(0.787+2.125 *($ Preoperative cervical length $<27.5 \mathrm{~mm})+1.463 * P P R O M+2.853 *$ Placental abruption)). 
Table 3

Multivariate logistic regression model analysis of the correlation between early preterm birth and late preterm birth and independent variables

\begin{tabular}{|c|c|c|c|c|c|c|}
\hline & $\begin{array}{l}P \\
\text { value }\end{array}$ & B & $\operatorname{Exp}(B)$ & $\begin{array}{l}95 \% \mathrm{Cl} \text { of } \\
\operatorname{Exp}(\mathrm{B})\end{array}$ & $\begin{array}{l}\text { Collinearity } \\
\text { Statistics }\end{array}$ & \\
\hline & & & & & Tolerance & VIF \\
\hline Maternal age & 0.724 & -.027 & 0.973 & $0.837-1.131$ & 0.708 & 1.413 \\
\hline Gestational age at surgery & 0.357 & -.139 & 0.870 & $0.648-1.170$ & 0.507 & 1.972 \\
\hline $\begin{array}{l}\text { Preoperative cervical length } \\
<27.5 \mathrm{~mm}\end{array}$ & 0.006 & 2.125 & 8.376 & $1.818-38.593$ & 0.695 & 1.439 \\
\hline Recipient's AFV >139.5mm & 0.283 & 1.131 & 3.098 & $0.394-24.385$ & 0.636 & 1.572 \\
\hline Stage of TTTS & 0.487 & -.526 & 0.591 & $0.134-2.609$ & 0.739 & 1.353 \\
\hline Multipara & 0.118 & 1.313 & 3.719 & $0.716-19.311$ & 0.713 & 1.402 \\
\hline Trocar diameter & 0.201 & 1.151 & 3.162 & $0.541-18.467$ & 0.523 & 1.913 \\
\hline Amnioreduction & 0.424 & -.907 & 0.404 & $0.044-3.732$ & 0.709 & 1.411 \\
\hline Sealing of puncture hole & 0.520 & .636 & 1.889 & $0.272-13.118$ & 0.778 & 1.286 \\
\hline Solomon & 0.106 & 1.474 & 4.366 & $0.732-26.028$ & 0.588 & 1.701 \\
\hline Without cervical cerclage & 0.152 & -2.041 & 0.130 & $0.008-2.114$ & 0.723 & 1.384 \\
\hline Amniotic fluid leakage & 0.326 & 1.336 & 3.805 & $0.264-54.856$ & 0.738 & 1.355 \\
\hline Chorioamnionitis & 0.905 & .171 & 1.187 & $0.071-19.802$ & 0.729 & 1.372 \\
\hline PPROM & 0.036 & 1.463 & 4.318 & $1.101-16.938$ & 0.776 & 1.288 \\
\hline Placental abruption & 0.043 & 2.853 & 17.343 & $\begin{array}{l}1.089- \\
276.239\end{array}$ & 0.790 & 1.266 \\
\hline Nonposterior placenta & 0.112 & 1.140 & 3.127 & $0.765-12.776$ & 0.893 & 1.120 \\
\hline Single intrauterine fetal death & 0.407 & -.785 & 0.456 & $0.071-2.916$ & 0.721 & 1.387 \\
\hline TAPS & 0.873 & -.275 & 0.760 & $0.026-21.870$ & 0.787 & 1.271 \\
\hline slUGR & 0.610 & -.579 & 0.561 & $0.061-5.180$ & 0.675 & 1.481 \\
\hline Constant & 0.787 & 1.046 & 2.846 & & & \\
\hline
\end{tabular}

According to the results of logistic regression analysis, the ROC curve was used to construct a combined prediction model of delivery before 32 weeks of pregnancy for the above risk factors of preterm delivery, including preoperative $\mathrm{CL}<27.5 \mathrm{~mm}$, PPROM, and placental abruption. As depicted in Figure 5 and Table 
4, the AUC of the three combined indicators combined was 0.799 , and $P$ value was less than 0.05 , indicating that all of them had a certain clinical value for predicting delivery before 32 weeks of pregnancy in the treatment of TTTS using FLS.

Table 4

The area under the curve of ROC

\begin{tabular}{|c|c|c|c|c|}
\hline \multirow[t]{2}{*}{ Area } & \multirow[t]{2}{*}{ Standard error ${ }^{a}$} & \multirow[t]{2}{*}{ Asymptotic significance ${ }^{b}$} & \multicolumn{2}{|c|}{ Asymptotic $95 \% \mathrm{Cl}$} \\
\hline & & & Offline & Online \\
\hline 0.799 & 0.049 & 0.000 & 0.704 & 0.895 \\
\hline
\end{tabular}

\section{Discussion}

FLS can significantly improve the pregnancy outcome of TTTS, but the occurrence of postoperative preterm delivery seriously affects the quality of life of living infants. The studies on the etiology and risk factors of preterm delivery have been previously reported. Papanna $R$ et al. [17] found that lower maternal age, TTTS stage II, history of preterm delivery, shortened cervical length, amniotic infusion, cannulas with the diameter of 12 French $(\mathrm{Fr})$, sealing of hole that not be punctured, and iatrogenic preterm premature rupture of membranes (iPPROM) were significantly associated with lower gestational age through multivariate analysis after controlling the operation center. Chmait et al. reported [18] that incomplete laser surgery, accidental septal stoma, triplet pregnancy, postoperative membrane separation, and nonposterior wall placental location are related factors that affect the gestational age of delivery. Similar to this study, a systematic review covering 34 studies [19] reported that the average gestational age of delivery at all centers was $32.4 \pm 1.3$ weeks. The differences among different centers were very larger, mainly due to the accumulation of surgical experience, patient selection, sample size and other factors. At present, the understanding about the related factors of preterm delivery is still limited. Thus, it is of great significance to understand the independent related factors that predict preterm delivery thus taking corresponding measures to prolong pregnancy.

Short cervix is an important factor for the early delivery of gestational weeks. Papanna R et al. [20] found that the risk of spontaneous preterm delivery before 34 weeks of gestation was significantly related to the length of preoperative cervix, and $\mathrm{CL}<28 \mathrm{~mm}$ was the critical value. In this study, ROC curve analysis showed that the risk of giving birth before 32 weeks of gestation was the highest when $\mathrm{CL}<27.5 \mathrm{~mm}$. In recent years, there have been four interventions to prevent preterm delivery after fetoscopic surgery: (1) Cervical cerclage; (2) Use gelatin sponge or hemostatic gauze to block the puncture hole; (3) Pessary; (4) Progesterone. Study has reported that cervical cerclage for patients with cervical length of $16-20 \mathrm{~mm}$ can prolong pregnancy and improve the 28-day survival rate of surviving infants [21]. In our center, gelatin sponge or hemostatic gauze was used to seal the puncture hole. Compared with the expectant treatment, there was no statistical difference in the gestational age of delivery $(P>0.05)$. Through analysis of eight patients who underwent cervical cerclage, it was found that cervical cerclage increased the risk of preterm delivery before 32 weeks of gestation $(P=0.049)$. The shorter average preoperative CL $(20.9 \mathrm{~mm}$ vs 28.7 
$\mathrm{mm}, P=0.026)$ in patients who underwent cervical cerclage might be a confounding factor. Similar to the study of Buskmiller $\mathrm{C}$ et al. [22], they used Propensity score analysis to show that cervical cerclage shortened the gestational age of delivery by nearly 2 weeks, and found that progesterone reduced the risk of delivery before 28 weeks of gestation. The recipient's AFV $\geq 139.5 \mathrm{~mm}$ before surgery increased the risk of preterm delivery at 32 weeks of gestation. Preterm delivery might be related to the rapid increase in intra-amniotic pressure caused by acute polyhydramnios. It is worth mentioning that Bergh EP et al. [23] attested that intra-amniotic pressure had nothing to do with the shortening of the $\mathrm{CL}$, and they also found that multiple term deliveries in the past might be associated with the reduction of intra-amniotic pressure. However, in our data, the gestational age at delivery of the multiparas seemed to be smaller than that of primiparas, but the difference was not statistically significant $(P>0.05)$. In this study, TTTS stage was not significantly correlated with the risk of preterm delivery before 32 weeks of gestation $(P=0.406)$, and was not statistically different from the gestational age of delivery $(P=0.586)$, but the twin survival rate had significant prognostic significance. Compared with TTTS stage I, the twin survival rates in TTTS stage III $(P=0.008)$ and TTTS stage IV $(P=0.044)$ were lower, and the difference was statistically significant. There was no significant difference in twin survival rates between TTTS stage I and TTTS stage II $(P>0.05)$.

Clinically, it is necessary to pay close attention to monochorionic diamniotic patients with the differences in the amniotic fluid volume and weight between the two fetuses to ensure early diagnosis, and try to intervene in the early TTTS to improve the survival rate of twins. A meta-analysis [24] revealed that the gestational weeks of delivery in TTTS at stage I-III were similar, and the gestational weeks of delivery at stage IV and V gradually were decreased, while a larger sample size was required for analysis. Mackie et al. [25] found that the intrauterine fetal and neonatal mortality of identical twins in patients with one fetal death in uterus before 28 weeks of pregnancy were significantly increased. Our data showed that intrauterine death of one fetus might have a positive effect on improving the gestational age at delivery ( $16.2 \%$ vs $26.4 \%$, but the difference was not statistically significant ( $P=0.053)$. In addition, it also suggested that the death of one fetus after FLS did not cause an increase in the mortality of surviving fetuses, which might be related to the protective effect of blocking the communicating blood vessels during fetoscopic surgery. It has been reported that the use of $12 \mathrm{~F}$ trocar was associated with an increased risk of preterm delivery $[16,17]$. In this study, the trocars of patients with anterior wall placenta were all selected $8 \mathrm{~F}$ model, and patients with posterior wall placenta who underwent surgery after 20 weeks of pregnancy should choose $8 \mathrm{~F}$ or $10 \mathrm{~F}$ model according to the intraoperative situation. While $12 \mathrm{~F}$ trocars have not been used, so there was no statistically significant difference between the trocar diameter and delivery before 32 weeks $(P=0.201)$.

PPROM is attributed to the non-healing characteristics of the membranes after trocar insertion [26-28], and trocar diameter and postoperative chorionic separation are also the risk factors for PPROM. In a study of Chmait et al. [29], the method of amniotic membrane repair could significantly prolong the number of days from iatrogenic preterm prelabor rupture of fetal membranes (iPPROM) to delivery, which was also associated with improved perinatal survival rate. There is no control group in this study, and there existed limitations of selection bias, therefore further research is needed. Placental abruption was 
significantly related to the risk of preterm delivery, which was a new finding in this study through analyzing the factors associated with preterm delivery. The occurrence of placental abruption might be related to the extensive tissue damage in the marginal area of the placenta caused by Solomon technique. Lanna MM et al. [30] found that compared with the selective placental vascular laser coagulation group under the fetal microscope, Solomon group had a higher perinatal survival rate $(77 \%$ vs $54 \%, P<0.001)$, but there was a higher risk of placental abruption in Solomon group. In this study, 9 patients $(10 \%)$ developed placental abruption after fetoscopic laser photocoagulation (FLP), and Solomon technique was used during the operation. Reducing the risk of placental abruption through improved surgical methods may be a direction to improve the gestational age at delivery. In order to avoid damage to the placental tissue without blood vessels on the chorionic plate, partial Solomon operation that only coagulates the equatorial anastomotic branch of the blood vessel and the adjacent area has been proposed and gradually applied in clinical practice. Our data were collected through prospective process to reduce recall bias and data missing, but there was a limitation of small sample size. Besides, because some patients did not deliver in our center, there were inconsistent indications for delivery.

The reasons that affect preterm delivery after FLS for TTTS are complicated, including preoperative, intraoperative and postoperative related factors. Preventive intervention for short cervix less than 27.5 $\mathrm{mm}$ is particularly important for prolonging pregnancy, but further research about specific measures is needed. Methods of preventing PPROM after FLS and treatment methods after PPROM are urgently needed. Partial Solomon procedure is a research direction to reduce the risk of placental abruption and prevent preterm delivery. Further study of intervention measures for these variables is beneficial to reduce the perinatal mortality and morbidity of TTTS patients after FLS.

\section{Declarations}

\section{Statements and Declarations}

All authors declare that they have no competing interests.

\section{Funding}

This study was supported by Medical Science and Technology Project of Henan Province (2018; No. 2018020196).

\section{Author contribution}

Genxia Li囚 Project development, Data analysis, Manuscript writing, Manuscript revising Shuhui Chu囚 Data management, Data analysis, Manuscript writing, Manuscript editing Shihong CuiðManuscript revising

Yajuan Xu『Manuscript revising 
Hezhou LiøData collection, Followed up

Fan Feng $₫$ Data collection, Followed up

Li Dong $₫$ Data collection, Followed up

Chunhua Cheng $₫$ Data analysis, Manuscript revising

Jiao Li®Data analysis, Manuscript revising

Mingkun Xie区Data analysis, Manuscript editing

Shuo Feng $₫$ Data management, Data analysis

Junya Zhang $₫ D$ ata collection, Manuscript editing

Manman Yang $₫$ Data collection, Manuscript editing

Mengyu Li®Data collection, Manuscript editing

Yujing HaoهData collection, Manuscript editing

\section{References}

1. Hack, K.E., et al., Placental characteristics of monoamniotic twin pregnancies in relation to perinatal outcome. Placenta, 2009. 30(1): p. 62-5.

2. Lewi, L., et al., The outcome of monochorionic diamniotic twin gestations in the era of invasive fetal therapy: a prospective cohort study. Am J Obstet Gynecol, 2008. 199(5): p. 514 e1-8.

3. Berghella, V. and M. Kaufmann, Natural history of twin-twin transfusion syndrome. J Reprod Med, 2001. 46(5): p. 480-4.

4. El Kateb, A. and Y. Ville, Update on twin-to-twin transfusion syndrome. Best Pract Res Clin Obstet Gynaecol, 2008. 22(1): p. 63-75.

5. Senat, M.V., et al., Endoscopic laser surgery versus serial amnioreduction for severe twin-to-twin transfusion syndrome. N Engl J Med, 2004. 351(2): p. 136-44.

6. Rossi, A.C. and V. D'Addario, Laser therapy and serial amnioreduction as treatment for twin-twin transfusion syndrome: a metaanalysis and review of literature. Am J Obstet Gynecol, 2008. 198(2): p. 147-52.

7. Chmait, R.H., et al., Stage-based outcomes of 682 consecutive cases of twin-twin transfusion syndrome treated with laser surgery: the USFetus experience. Am J Obstet Gynecol, 2011. 204(5): p. 393 e1-6.

8. Cobo, T., et al., Clinical and biochemical predictors of very preterm birth in twin-to-twin transfusion syndrome treated by fetoscopy. Am J Obstet Gynecol, 2011. 204(1): p. 58 e1-5. 
9. Robyr, R., et al., Cervical length as a prognostic factor for preterm delivery in twin-to-twin transfusion syndrome treated by fetoscopic laser coagulation of chorionic plate anastomoses. Ultrasound Obstet Gynecol, 2005. 25(1): p. 37-41.

10. Schou, K.V., et al., Long-Term Neurodevelopmental Outcome of Monochorionic Twins after Laser Therapy or Umbilical Cord Occlusion for Twin-Twin Transfusion Syndrome. Fetal Diagn Ther, 2019. 46(1): p. 20-27.

11. Lenclen, R., et al., Neonatal outcome in preterm monochorionic twins with twin-to-twin transfusion syndrome after intrauterine treatment with amnioreduction or fetoscopic laser surgery: comparison with dichorionic twins. Am J Obstet Gynecol, 2007. 196(5): p. 450 e1-7.

12. Gheorghe, C.P., et al., Neonatal Outcomes and Maternal Characteristics in Monochorionic Diamniotic Twin Pregnancies: Uncomplicated versus Twin-to-Twin Transfusion Syndrome Survivors after Fetoscopic Laser Surgery. Fetal Diagn Ther, 2020. 47(2): p. 165-170.

13. Salomon, L.J., et al., Emergency cerclage in cases of twin-to-twin transfusion syndrome with a short cervix at the time of surgery and relationship to perinatal outcome. Prenat Diagn, 2008. 28(13): p. 1256-61.

14. Malshe, A., et al., Preterm delivery after fetoscopic laser surgery for twin-twin transfusion syndrome: etiology and risk factors. Ultrasound Obstet Gynecol, 2017. 49(5): p. 612-616.

15. Chmait, R.H., et al., Risks of Preterm Premature Rupture of Membranes and Preterm Birth Post Fetoscopy Based on Location of Trocar Insertion Site. Am J Perinatol, 2018. 35(8): p. 801-808.

16. Hessami, K., et al., Prenatal risk factors of neurodevelopmental impairment after fetoscopic laser photocoagulation for twin-twin transfusion syndrome: a systematic review and meta-analysis. Ultrasound Obstet Gynecol, 2021.

17. Papanna, R., et al., Risk factors associated with preterm delivery after fetoscopic laser ablation for twin-twin transfusion syndrome. Ultrasound Obstet Gynecol, 2014. 43(1): p. 48-53.

18. Chmait, R.H., et al., Perioperative characteristics associated with preterm birth in twin-twin transfusion syndrome treated by laser surgery. Am J Obstet Gynecol, 2013. 209(3): p. 264 e1-8.

19. Akkermans, J., et al., Twenty-Five Years of Fetoscopic Laser Coagulation in Twin-Twin Transfusion Syndrome: A Systematic Review. Fetal Diagn Ther, 2015. 38(4): p. 241-53.

20. Papanna, R., et al., Cervical length in prediction of preterm birth after laser surgery for twin-twin transfusion syndrome. Ultrasound Obstet Gynecol, 2015. 45(2): p. 175-82.

21. Papanna, R., et al., Cerclage for cervical shortening at fetoscopic laser photocoagulation in twin-twin transfusion syndrome. Am J Obstet Gynecol, 2012. 206(5): p. 425 e1-7.

22. Buskmiller, C., et al., Interventions to prevent preterm delivery in twin-twin transfusion with short cervix. Ultrasound Obstet Gynecol, 2021.

23. Bergh, E.P., et al., Effect of intra-amniotic fluid pressure from polyhydramnios on cervical length in patients with twin-twin transfusion syndrome undergoing fetoscopic laser surgery. Ultrasound Obstet Gynecol, 2019. 54(6): p. 774-779. 
24. Di Mascio, D., et al., Outcome of twin-twin transfusion syndrome according to Quintero stage of disease: systematic review and meta-analysis. Ultrasound Obstet Gynecol, 2020. 56(6): p. 811-820.

25. Mackie, F.L., et al., Prognosis of the co-twin following spontaneous single intrauterine fetal death in twin pregnancies: a systematic review and meta-analysis. BJOG, 2019. 126(5): p. 569-578.

26. Gratacos, E., et al., A histological study of fetoscopic membrane defects to document membrane healing. Placenta, 2006. 27(4-5): p. 452-6.

27. Devlieger, R., et al., An organ-culture for in vitro evaluation of fetal membrane healing capacity. Eur $\mathrm{J}$ Obstet Gynecol Reprod Biol, 2000. 92(1): p. 145-50.

28. Devlieger, R., et al., Fetal membrane healing after spontaneous and iatrogenic membrane rupture: a review of current evidence. Am J Obstet Gynecol, 2006. 195(6): p. 1512-20.

29. Chmait, R.H., et al., Amniopatch treatment of iatrogenic preterm premature rupture of membranes (iPPROM) after fetoscopic laser surgery for twin-twin transfusion syndrome. J Matern Fetal Neonatal Med, 2017. 30(11): p. 1349-1354.

30. Lanna, M.M., et al., Increased risk of placental abruption after solomon laser treatment of twin-twin transfusion syndrome. Placenta, 2017. 53: p. 54-56.

\section{Figures}




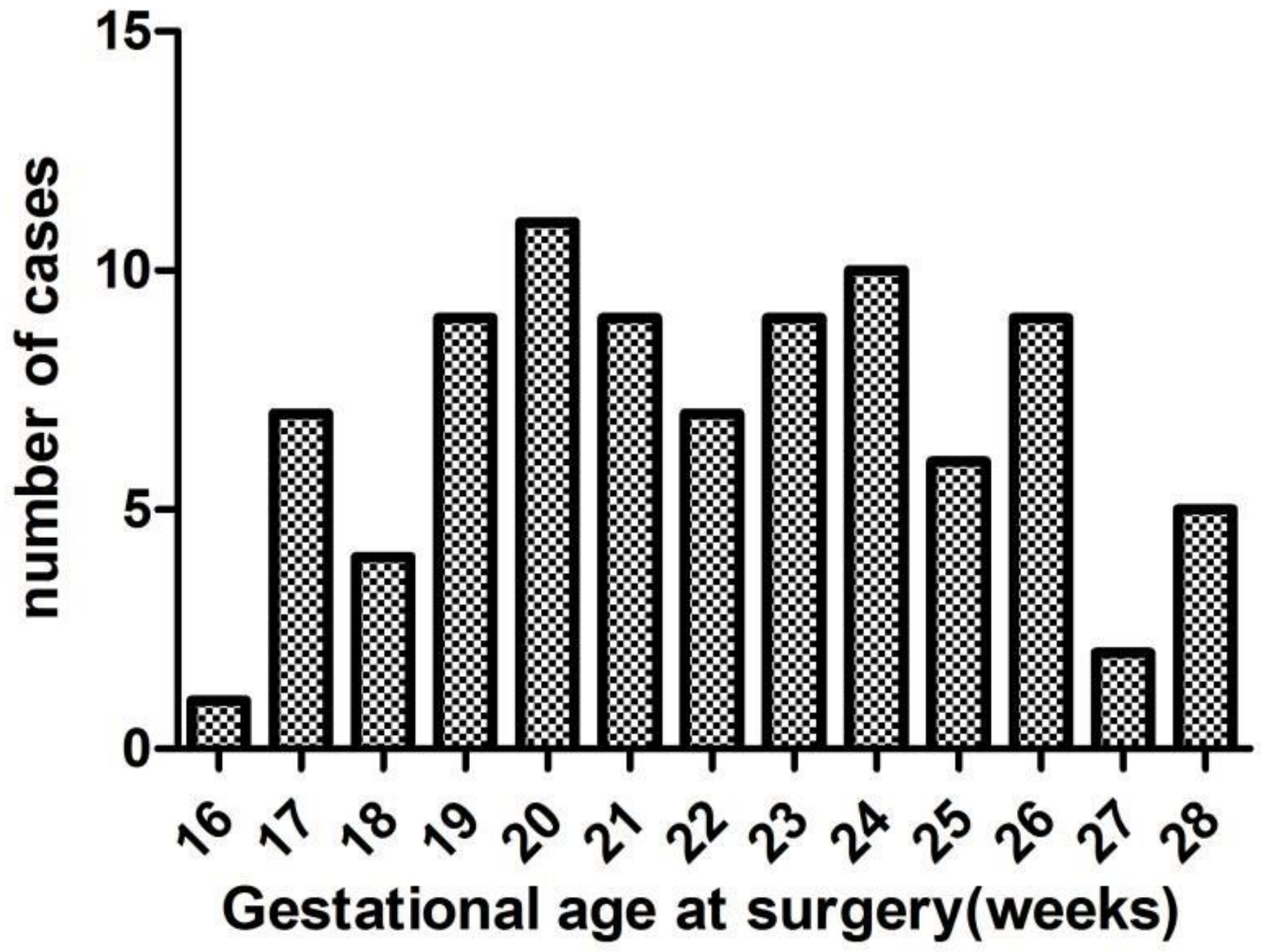

Figure 1

The distribution of gestational age at surgery in 90 patients. 


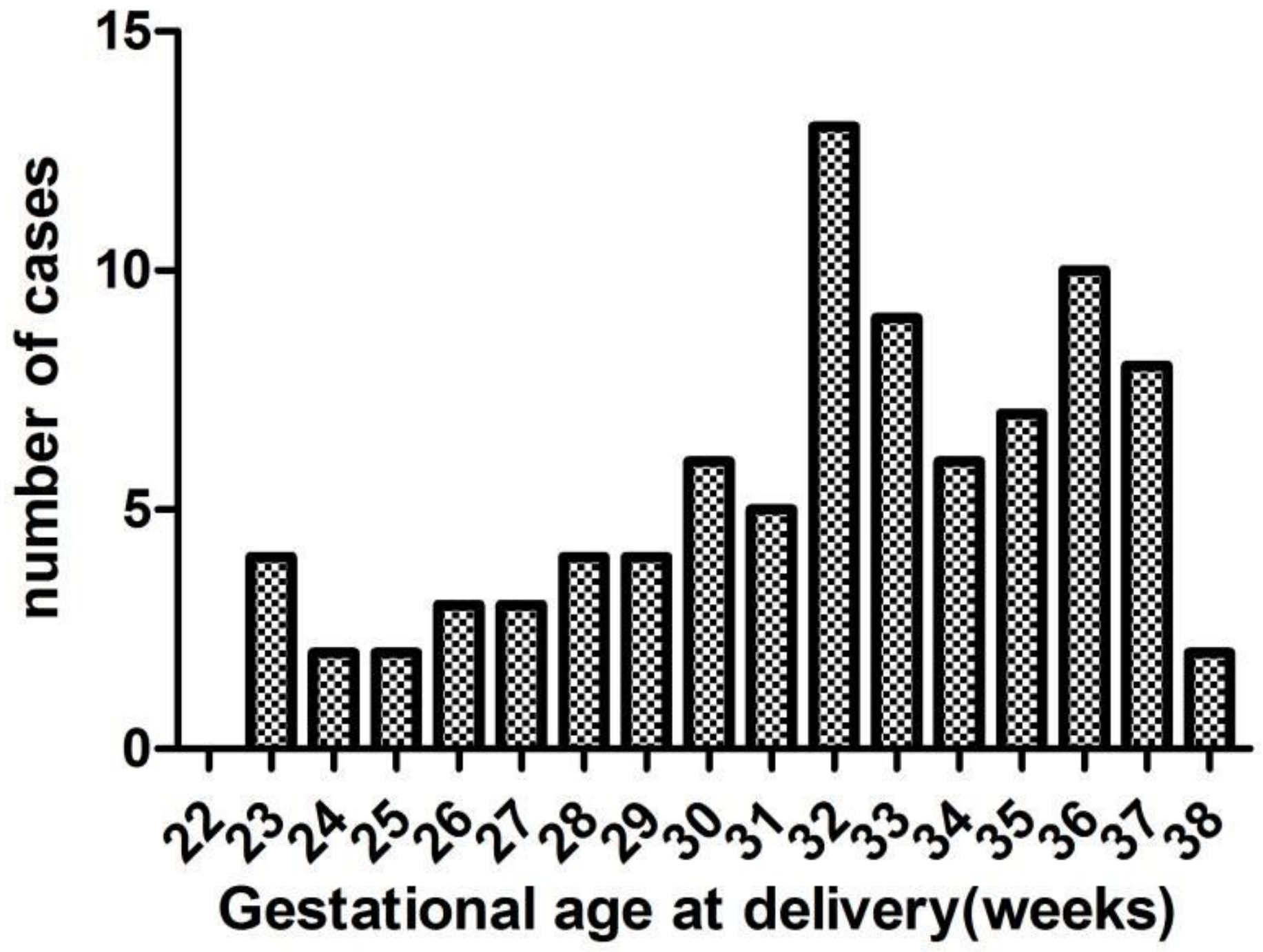

Figure 2

The distribution of gestational age at delivery in 90 patients. 


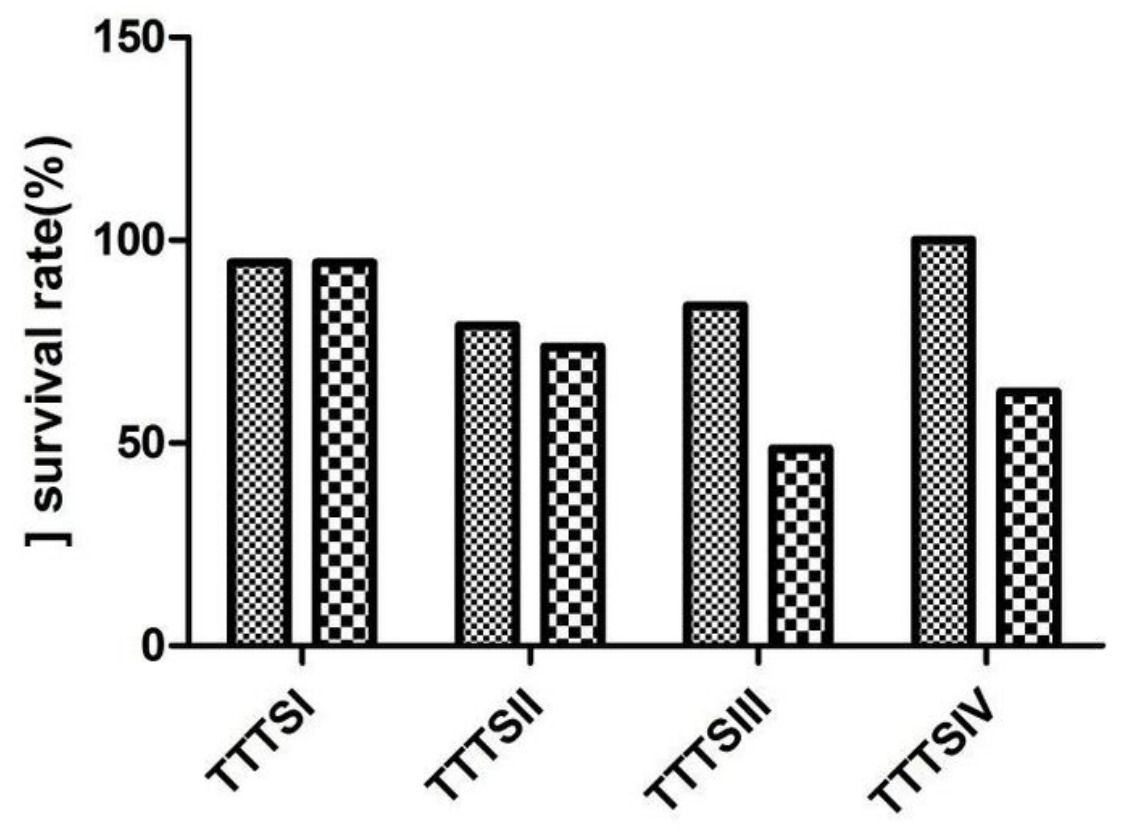

$\approx$ Survival rate of at least one

Ex Twin survival rate

Figure 3

The survival rate of at least one child and twin survival rate in TTTS patients at stage I-IV.
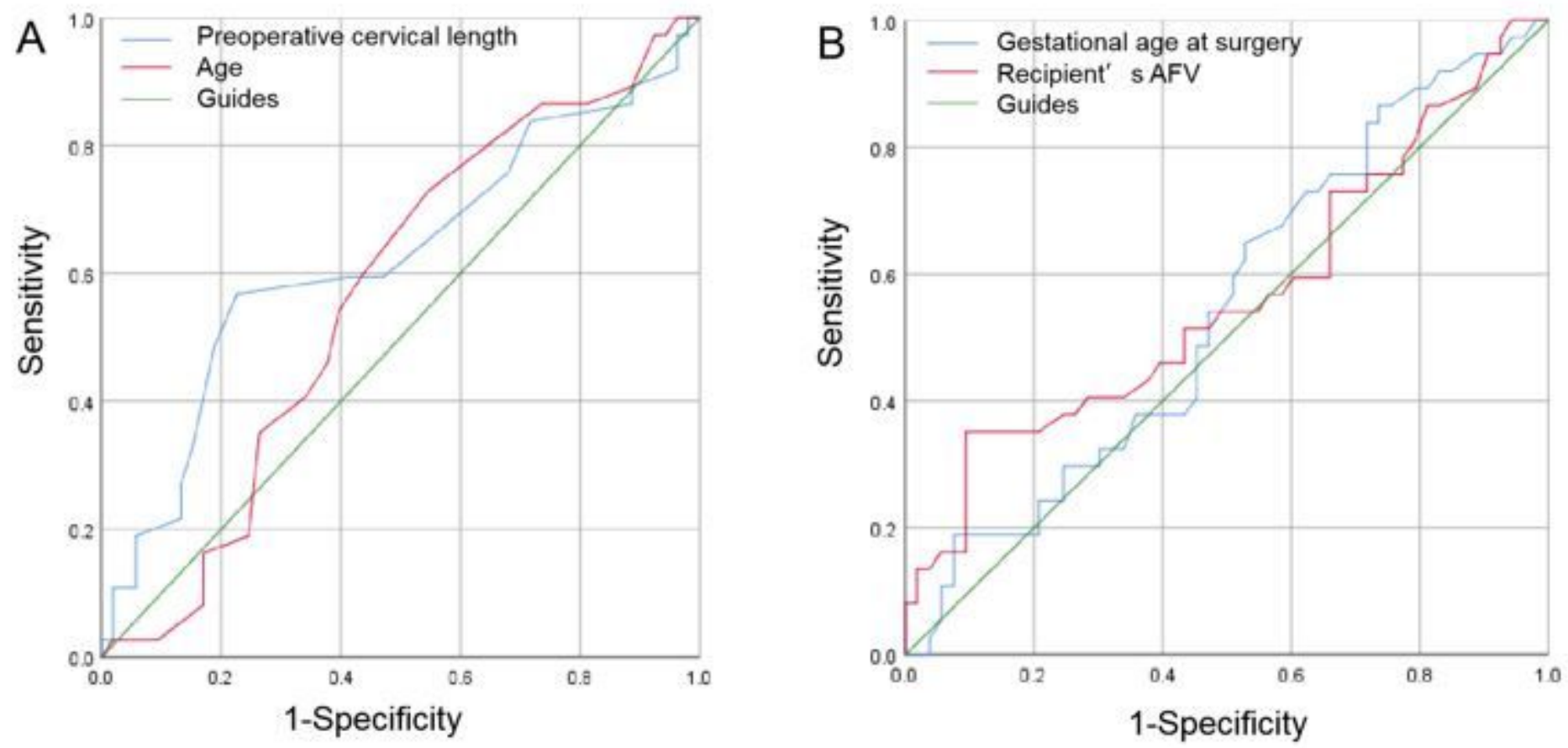

Figure 4

ROC curve analysis about the correlation of CL and recipient's AFV with delivery before 32 weeks of gestation. 


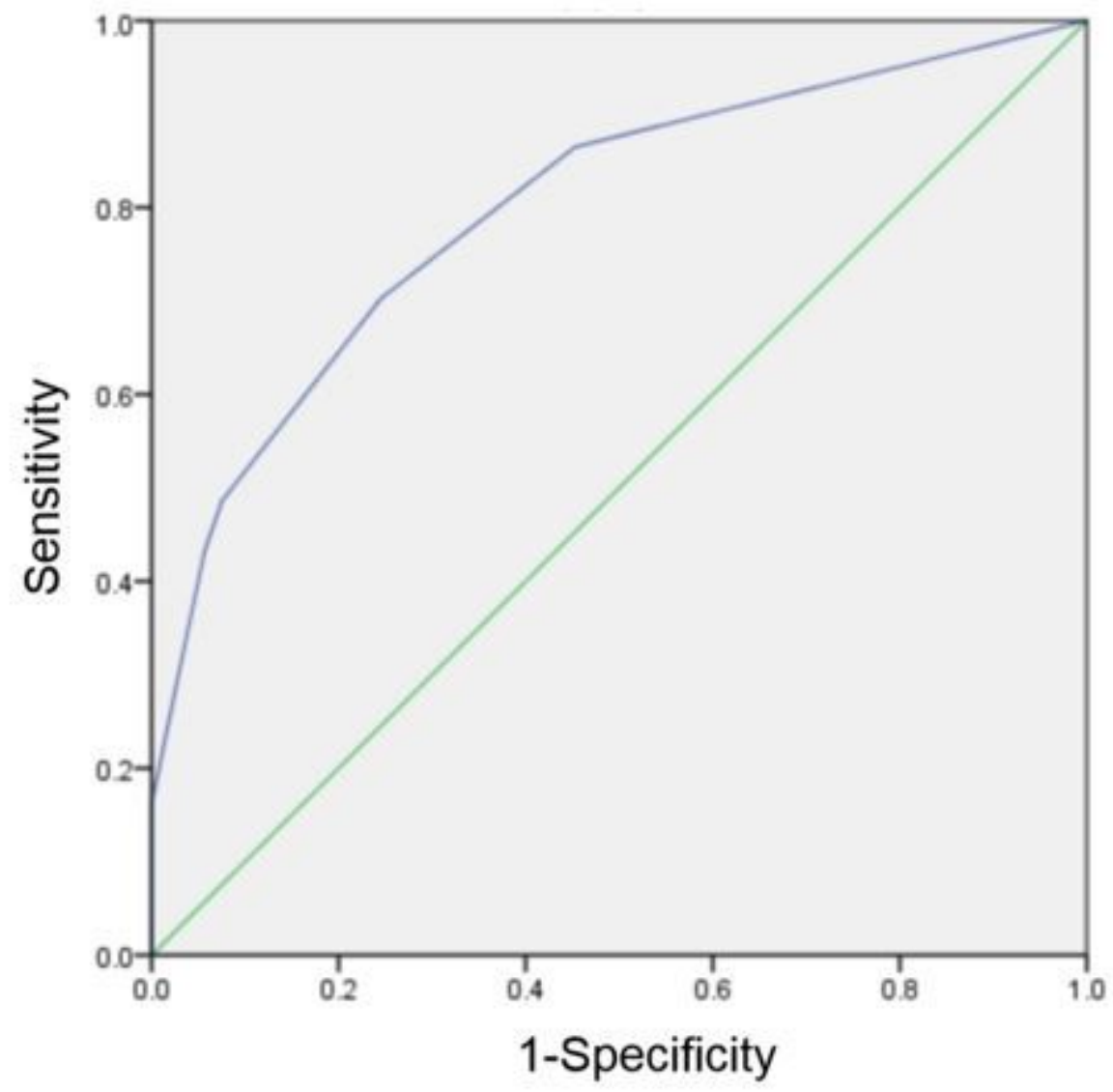

Figure 5

ROC curve analysis of preoperative CL, PPROM, and placental abruption in predicting delivery before 32 weeks of pregnancy. 